\title{
Measures to Avoid the Pollution Flashover
}

\author{
Yi Wang ${ }^{1}$, Qiang Zhao ${ }^{1}$, Xinyu $\mathrm{Li}^{1}$, Chuang Wang ${ }^{1}$, Pin Lv ${ }^{2}$, Qingguo Meng ${ }^{2}$, \\ Feng Shi ${ }^{1}$, Qiang Liu ${ }^{1}$, Boyu Shi ${ }^{1}$ \\ ${ }^{1}$ Fushun Power Supply Company, Liaoning Electric Power Company Limited, State Grid, China, \\ ${ }^{2}$ Manzhouli City Power Company Limited, State Grid, China
}

Keywords: Pollution Flashover, Insulator, Salt Density, Clean Up

\begin{abstract}
The pollution flashover is short for the filthy external insulation flashover of power transmission and transformation equipment. The three elements of pollution flashover are filth, damp and voltage. This paper analyzed that Fushun is the serious pollution area. Because of user substation does not clean it carefully, which lead to a seven pollution flashover accident in the summer of 2016 (heavy rainfall, the hot weather, "wet" insulator surface).By analyzing the causes of pollution flashover, there are many kinds of technical measures to prevent pollution flashover, but the regular clean up is the most basic, the most convenient and economical way to prevent pollution flashover for users so far.
\end{abstract}

\section{Introduction}

The pollution flashover is the surface flashover of insulator, The three elements of pollution flashover are filth, damp and voltage ${ }^{[6]}$. With the development of the economy, not only brings a welcome change, but also serious pollution. Pollution brings bad influence to the national life, and brings trouble to the safe and stable operation of the electric power system. Pollution flashover is the problem that power system have to face. Pollution flashover occurs in serious polluted areas, the consequence is very serious. The lightest consequences is transmission line tripping, the most serious consequences is blackout in large area. Fushun as an old industrial base, the pollution is serious, so work pressure of anti pollution flashover is very heavy. In recent years, Fushun is in the stage of economic transformation, its industrial distribution changes frequently. The migration of pollutant source caused pollutant area changed, which bring a big problem to anti pollution flashover work. Especially in the summer of 2016,rainfall is heavy , the weather is hot, humidity is usually greater than 85\%.In recent years, the condition-based maintenance is implemented, equipments do not be cleaned carefully, especially the user substation is never cleaned, which lead to seven pollution flashover accident in the summer.

\section{The Cause of the Pollution Flashover}

The pollution flashover process of porcelain and glass insulator can be divided into four stages in general. Pollution flashover is a complex change process which involving electricity, heat and chemicals phenomenon.

Firstly, the surface pollution of insulators. Porcelain and glass insulator exposure in the atmospheric environment for a long time. The atmospheric particulate matter, ground dust and other pollutant will inevitably fall on its surface, and its electric adsorption could make its surface filth higher than other objects. The concrete composition of filthy varies with the area of insulators. The more serious the polluted atmosphere area is, the more serious the insulator pollution is. At the same time, the insulator is cleaned by wind and rain. The heavy rain has a clean effect on the pollution of the insulator surface. In the dry season, filth on the pollution of the insulator surface accumulate gradually. In the rainy season, the cleaning effect of rain reduce the amount of the insulator pollution significantly, especially the upper surface pollution is less than the lower surface pollution significantly. In the natural environment, the insulator surface repeated the process of filth accumulation and natural cleaning, usually kept certain filth on the surface of insulators. 
Secondly, the wet filthy layer. In the dry condition, the pollution of the insulator surface is not conductive mostly. Only when the filthy become damp and wet, the electricity form a conductive layer on the insulator surface. The flashover voltage on the surface of insulator will reduce obviously. The degree of the reduction is associated with the electrical conductivity. The experience of operating shows that the wet weather such as fog, dew, drizzle cause pollution flashover of insulators easily. These weather conditions can make the filthy layer fully wet, make the electrolyte on the filthy layer completely dissolved, but still not make the filthy layer was washed away.

Thirdly, the formation of dry area and the generation of partial discharge. On the condition of wet weather, filthy on the surface of the insulator is fully wet. For porcelain, glass and other hydrophilic materials. Insulator surface can form a layer of conductive water film, which greatly increased the leakage current along the surface of the insulator. The joule heat caused by leakage current will drying the wet sludge layer gradually. In the area with larger density current, the dry area is produced first, the dry area has a great deal of surface resistance. The voltage added on opposite sides of the insulator is mainly borne by the dry area. When the electrical field strength of dry area is more than the critical electrical field strength that air discharge along the dielectric surface, it will occur the along partial discharge. This kind of partial discharge long the surface is unstable and be the intermittent pulse state. According to different conditions, the form of partial discharge may be spark discharge, brush discharge, or the local electric arc across the dry area. When spark discharge ends, it has been a dry area. The leakage current is limited by high resistancedry of dry area. The drying effect of leakage current is almost stopped, then the moisture from the atmosphere can make the dry area to be wet, thereby on the higher place of an electrical field strength will produce new spark discharge, so cycle development.

Fourthly, the partial arc development to flashover. If the insulator is filthy seriously, insulator surface is fully affected with damp, and the leakage distance of insulators is small, there will be a strong partial discharge phenomenon. On this condition, the discharge will become the arc discharge across dry area. The arc is red and yellow, and its shape like branches frequent scale. In the temperature in plasma channel can be increased to the extent of free. After the partial arc comes, the heat effect of arc expands dry area unceasingly, arc rotating along the dry area, constantly adapt to its length. When dry area expanded to arc unsustainably, arc will extinguish itself. Because of arc extinguishing and leakage current decreasing, the dry dirt layer return to damp gradually in the damp environment. Thus come into being new dry area and partial arc. With the wet condition around, continue to reduce the resistance of fouling layer continuously, increase the leakage current, and the phenomenon of intermittent partial discharge is more and more intense. The partial arc will constantly stretching along the insulator surface, producing the cross-regional partial long arc, eventually arc develop rapidly, until penetration electrode on both ends of the insulator, thus completing the process of flashover.

\section{Examples of Pollution Flashover Accidents}

Pollution flashover often happens in wet weather (fog, snow melt, rain, etc.).In wet weather, air humidity is high, the filth of the insulator absorb moisture in the air, which is called the absorption moisture process. When the humidity reaches a certain degree, the soluble substances will be dissolved, and form a conductive channel. Leakage current will pass the insulator along the channel to discharge. Finally with the current increases, it will develop into a flashover, and lead to serious consequences.

Electrical equipments in a user substation occur fouling phenomenon during the using process in recent years. Pollution flashover accidents in humid conditions are shown in figure 1 and figure 2 below. Because the electricity inspector did not carefully guidance, neither to urge the electricity power units to clean when power cut. It lead to the pollution flashover accident happened on the July 15, 2016, and the direct economic loss is 90000 yuan. 


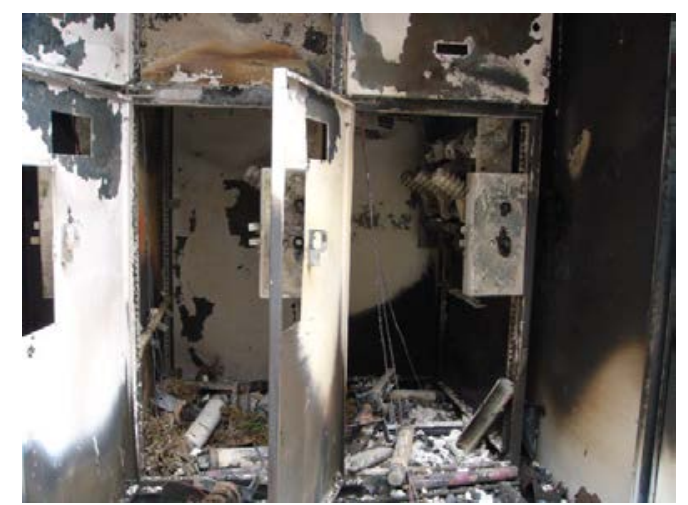

Fig.1 The pollution flashover of user switchgear

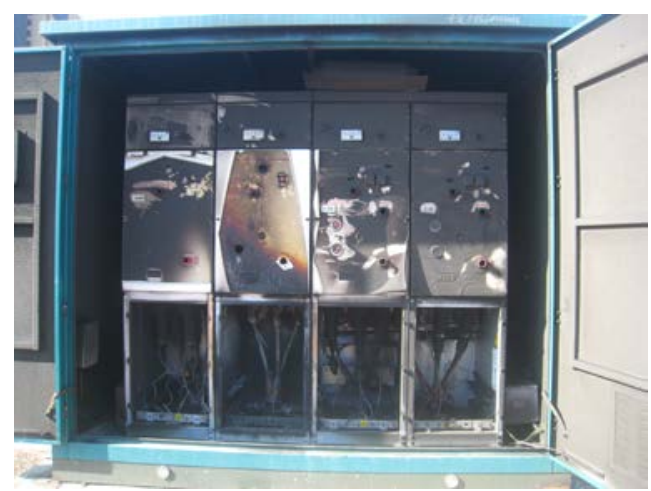

Fig.2 The pollution flashover of line ring main unit

\section{The Analysis of Pollution Flashover Accidents}

Equivalent salt deposit density (salt density for short, the ESDD) is characteristic parameters representing the polluted degree of insulator surface. Salt density refers to conductive particles of the filth on the insulator surface equivalent for the content of sodium chloride under the same conditions, the unit is $\mathrm{mg} / \mathrm{cm}^{2}$. The salt density parameter can directly shows the content of conductive particles on the insulator surface. The salt density is measured when the insulator pollution reach the saturated condition, namely the insulator pollution accumulate deposition for years will reach saturation. In general,3 to 5 years of salt density is stable. The value of salt density is very important for division of line pollution area and the configuration of external insulation. When the insulator pollution is saturated, the test result of insulator salt density is the most correct. By means of free hang and the running insulator to demonstrate the exact time for insulator pollution to reach saturation ${ }^{[1]}$.

The pollution level of lines, power plants and substations were divided into a, b, c, d, e,which are shown in table $1^{[3]}$. 
Tab.1 The pollution level of lines, power plants and substations

\begin{tabular}{|c|c|c|c|}
\hline \multirow[b]{2}{*}{$\begin{array}{l}\text { Pollution } \\
\text { level }\end{array}$} & \multirow[b]{2}{*}{ characteristics of pollution wet } & \multicolumn{2}{|c|}{ salt density, $\mathrm{mg} / \mathrm{cm}^{2}$} \\
\hline & & line & $\begin{array}{c}\text { Power plant and } \\
\text { substation }\end{array}$ \\
\hline $\mathrm{a}$ & $\begin{array}{l}\text { Clean atmosphere areas and less polluted areas } \\
\text { far from the coast more than } 50 \mathrm{~km} \text {. }\end{array}$ & $a \leqslant 0.03$ & - \\
\hline $\mathrm{b}$ & $\begin{array}{l}\text { Atmospheric lightly polluted areas, industrial } \\
\text { areas and low population density areas, areas far } \\
\text { from the coast } 10 \mathrm{~km} \sim 50 \mathrm{~km} \text {.In flashover season } \\
\text { like dry and less fog (including drizzle) or large } \\
\text { rainfall. }\end{array}$ & $0.03<b \leqslant 0.06$ & $b \leqslant 0.06$ \\
\hline c & $\begin{array}{l}\text { The medium pollution areas, light saline-alkali } \\
\text { areas and furnace smoke pollution areas, areas } \\
\text { far from the coast } 10 \mathrm{~km} \sim 50 \mathrm{~km} \text {.In flashover } \\
\text { season like wet and fog (including drizzle) but } \\
\text { less rainfall. }\end{array}$ & $0.06<_{\mathrm{c}} \leqslant 0.1$ & $0.06<_{\mathrm{C}} \leqslant 0.1$ \\
\hline$d$ & $\begin{array}{l}\text { The serious pollution areas, heavy fog and } \\
\text { heavy saline-alkali areas, areas far from the coast } \\
1 \mathrm{~km} \text { to } 3 \mathrm{~km} \text {.industrial and high population } \\
\text { density areas, serious polluted areas away from } \\
\text { the chemical pollution and furnace smoke filthy } \\
300 \mathrm{~mm} \sim 1500 \mathrm{~mm} \text {. }\end{array}$ & $0.1<\mathrm{d} \leqslant 0.25$ & $0.1<\mathrm{d} \leqslant 0.25$ \\
\hline e & $\begin{array}{l}\text { Atmospheric polluted especially serious areas, } \\
\text { areas far from the coast less than } 1 \mathrm{~km} \text {, away } \\
\text { from the chemical pollution and furnace smoke } \\
\text { filthy less than } 300 \mathrm{~mm} \text {. }\end{array}$ & $0.25<\mathrm{e} \leqslant 0.35$ & $0.25<\mathrm{e} \leqslant 0.35$ \\
\hline
\end{tabular}

The salt density of substations are tested on July 18th, 2016.The purpose is to verify if the switchgear fire accident was caused by the pollution flashover. Test results show the value of salt density is $0.18 \mathrm{mg} / \mathrm{cm}^{2}$, belong to "d".In damp and sultry weather "perspire" on the insulator surface, satisfy conditions of the pollution flashover, so the pollution flashover accident happens.

\section{The Measures to Prevent the Pollution Flashover Accident}

The three elements of pollution flashover are filth, damp and voltage. As long as one of the elements is damaged, the occurrence of pollution flashover can be avoided. Based on this theory, formulated the following antifouling flash measures:

1. To promote the harm caused by pollution flashover to the user.

2. According to the antifouling level, replace the ordinary insulator with the anti-pollution insulator in serious filth areas.

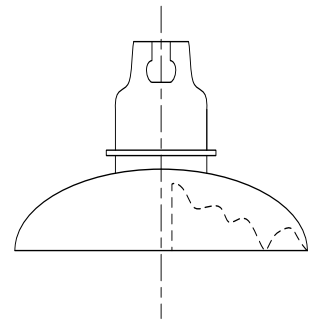

Normal insulator

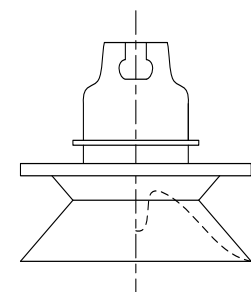

Double umbrella insulator (antifouling)

3. To clean equipment every year

4. To paint the RTV anti pollution flashover

5. Recommend the particularly serious users to use (change) silicone rubber insulation equipment. 


\section{Conclusions}

Through the comprehensive analysis, based on the principle of seeking truth from facts, the work of anti pollution flashover goes smoothly. Because Fushun is an old industrial city, the economy is modest, funds is insufficient. So the anti pollution flashover for users should work on the manual cleaning. Users know little about the dangers of pollution flashover. Electricity inspector should be stepping up efforts to propaganda, supervise and monitor users clean the substation equipment regularly, to make the grid strong, and satisfy the user .Although, there are many kinds of technical measures to prevent pollution flashover, but the regular clean up is the most basic, convenient and economical way to prevent pollution flashover.

\section{References}

[1]Yu Huayu, Wencheng Xu, Gang Shen, High voltage electrical equipment antifouling flash and charged cleaning technology. Beijing: China Electric Power Press 2006.

[2]Zhenya Liu, External insulation uhv ac transmission system. Beijing: China Electric Power Press 2008.

[3]Cangchang Wang,Fuqi Li,Shengyou Gao,On-line monitoring and fault diagnosis of power equipment.Qinghua University Press 1999.

[4]The electric power research institute electricity antifouling flash technology question and answer.China Electric Power Press 2009.

[5]Zhixian Qiu,High voltage composite insulator and its application.China Electric Power Press 2006.

[6]Grid antifouling flash technology question and answer.China Electric Power Press 2009. 